\title{
The Effects of Taxing Sugar-Sweetened Beverages across different Income Groups
}

\author{
Anurag Sharma, Katharina Hauck, Bruce Hollingsworth, Luigi Siciliani
}

\begin{abstract}
Taxes on sugar sweetened beverages (SSBs) - so called 'soda taxes' are currently receiving considerable attention as a potentially very effective policy intervention in the fight against rising obesity rates all-over the world. By increasing the price of sugar sweetened beverages, taxes promise to reduce sugar intake and subsequently bodyweight of individuals. However, there are concerns that such taxes are regressive, i.e. burden lower income groups more. This paper explores this issue by estimating the impact of SSB taxes on consumption, bodyweight and tax burden for low, middle, and high-income groups using an Almost Ideal Demand System and 2011 Household level panel data. A significant contribution of our paper is that we compare two types of SSB taxes recently advocated by policy makers: A $20 \%$ flat rate sales (valoric) tax, and a 20 cent per litre volumetric tax. Censored demand (which arises when households do not consume certain beverages at all) is accounted for using a two-step procedure. We find that the volumetric tax would result in a greater yearly per capita weight loss than the valoric tax $(0.9 \mathrm{~kg}$ vs $0.4 \mathrm{~kg})$. The difference between the change in weight is substantial for the target group of heavy purchasers of SSBs in low-income households, with a weight reduction of $4.4 \mathrm{~kg}$ for the volumetric, and $2.3 \mathrm{~kg}$ for the valoric tax. The average per capita tax burden on low-income households is $\$ 17.90$ per capita per year $(0.21 \%$ of income) compared to $\$ 15.20$ for high-income households ( $0.064 \%$ of income) for the valoric tax, and $\$ 13.80(0.15 \%)$ and $\$ 10.10(0.04 \%)$ for the volumetric tax. In summary, the tax burden is lower and weight reduction is considerably higher under a volumetric tax. These findings have significant policy implications for obesity reduction strategies.
\end{abstract}

Keywords: Sugar-sweetened beverages tax; tax burden; obesity; tax regressivity; weight loss.

JEL: I12, I19 


\section{Introduction}

Taxes on sugar-sweetened beverages (SSBs) are currently advocated by many policy makers and public health experts as an effective policy intervention that can help stem the rising prevalence of obesity and associated diseases. There are several examples of such a tax being implemented already. By mid-2011, forty states in the USA had imposed a carbonated soft drink (soda) $\operatorname{tax}^{1}$, with an average sales tax on regular (i.e. non diet) soda in food stores of $3.5 \%$ across all states, and a maximum tax of $7 \%$ in the states of Indiana, Mississippi, New Jersey and Rhode Island (Bridging the Gap Program 2011). In Europe, France recently raised a tax on SSBs from 3 to 6 Euro cents per litre; Hungary introduced a tax on fatty foods, plus higher tariffs on SSBs; and in the United Kingdom the Prime Minister has stated that a tax on unhealthy products is being considered (Press Association 2011). Other countries, for example Peru, Israel and Ireland, are also considering such taxes. The UN high level summit on non-communicable disease has noted that food taxes and subsidies have a role to play in promoting a healthy diet (United Nations 2011).

Despite this enthusiasm for SSB taxes, a recent review on soft drink taxes concluded that there has been relatively little critical analysis of SSB taxes and that evidence for informing policy-making is inadequate (Thow, Heywood et al. 2011, Mytton, Clarke et al. 2012). Independent nutrition experts almost unanimously agree that consumption of SSBs leads to weight gain (Vartanian, Schwartz et al. 2007), and many state that it may be the single largest driver of the obesity epidemic (Brownell and Frieden 2009). Evidence on a significant relationship mainly originates from observational studies (Allison and Mattes 2009), and while there are published studies that find no or only small effects, it has been suggested that many of these studies are conducted by authors supported by the beverage industry (Vartanian, Schwartz et al. 2007). Some public health advocates see history repeating itself when comparing the strategies of tobacco companies and now the beverage industry to prevent taxes on their products (Brownell and Warner 2009). Apart from denying the negative health impact of their products, the beverage industry has on occasion contributed to some self-regulation efforts such as selective abolition of vending machines in schools (Sharma, Teret et al. 2010), recent marketing that there is a choice, and political lobbying, all with the objective to prevent the introduction of commercially damaging policies, just like

\footnotetext{
${ }^{1}$ Non diet carbonated soft drinks, non diet (not sugar free) sodas, and sugar sweetened beverages (SSBs) are often generally referred to as SSBs. We break these down as applicable in our analyses.
} 
tobacco companies 30 years before. It is telling that while contributions in the USA to federal candidates and political committees from the tobacco industry fell drastically from US $\$ 10.6 \mathrm{M}$ in 1996 when legal battles were at their peak to US\$3.2M in 2010, over the same period, contributions from the food processing and food retail industry have tripled from US\$ 10M to just under US\$ 30.5M in 2010 (Center for Responsive Politics 2013).

Economic theory predicts that taxes raise the price of a normal good to consumers, resulting in a reduction in the quantity demanded and consumed. A SSB tax would impose a sales or excise tax on soft or soda drinks, and other carbonated and un-carbonated drinks, including sports and energy drinks, sweetened with sugar, corn syrup, or other caloric sweeteners. The beverage industry is putting forward two main arguments against introduction of such a tax on SSBs (Americans Against Food Taxes 2013). First, they claim that any impact of a soft drink tax would be trivial because soft drink consumption is a relatively small part of the diet of overweight individuals. Studies using natural experiments, controlled trials of price changes in closed environments, or modelling, have found that a soft drinks tax does reduce consumption and, in turn, reduces the prevalence of obesity (Mytton, Clarke et al. 2012). However, it seems that the tax has to be quite substantial to make a difference (Powell and Chaloupka 2009). Second, the beverage industry argues that a tax would be regressive: poor people would pay a greater proportion of their income in tax than the rich, or, as the American Beverage Association (ABA) put it, a tax would "just further burden working families already struggling in this trying economy" (Americans Against Food Taxes 2013). Evidence on regressivity is inconclusive, with some studies confirming the statements of the ABA (Leicester and Windmeijer 2004, Nnoaham, Sacks et al. 2009, Allais, Bertail et al. 2010), some suggesting that regressivity is negligible because poor households would lower consumption proportionately more than wealthier households (Smed, Jensen et al. 2007), and some even concluding that such a tax could be progressive (Nordström and Thunström 2011).

In the absence of robust evidence, public health advocates counter any regressivity argument to justify SSB taxes by emphasizing that the health gains of a tax are likely to be progressive (Brownell and Frieden 2009), because poorer people consume less healthy food and have a higher incidence of most diet related diseases, notably cardiovascular disease (British Heart Foundation 2012). Consequently the absolute reduction in disease incidence would be greater among poorer groups, assuming similar dietary changes. This is an important assumption, because if demand for SSBs is less elastic for the poor, i.e. less reactive to price changes, they would have a smaller dietary change than the rich, and consequently experience lower weight 
reduction and less health gains. The extent of health improvement due to taxes is often seen as uncertain, occurs in the future and is difficult to quantify in monetary terms, whereas any tax burden has an immediate financial impact. This may make governments reluctant to impose such a tax on their electorate (Laurance 2009). Denmark provides a real-life example for such concerns; political pressure led to abolition of a tax on fat in food products after only one year (Khazan 2012).

The objective of this paper is to contribute to the current debate on soft drink taxes by investigating (i) whether lower income groups respond differently to a SSB tax and thereby have differing health gains, and (ii) whether lower income groups have a higher tax burden either in absolute value or as proportion of their income in SSB taxes compared to the rich. One innovative contribution of our paper is that we compare the tax burden and change in body weight under a $20 \%$ valoric (value added) tax on the price of SSBs, and a volumetric tax (20 cents/litre) on quantities of SSBs purchased. It has been suggested recently that a volumetric tax might be more effective in increasing price of multipacks of SSBs sold on special offer and will be more effective at targeting heavy drinkers of SSBs than a valoric tax (Sustain 2013), but evidence on the comparative welfare impacts is not currently available this paper is the first to provide such evidence. A further innovation at a methodological level is that we allow for the possibility that not all households consume all beverages, i.e. that demand for some beverages is censored at zero. This issue has been difficult to deal with in previous studies. It is of concern since, if not accounted for, it may lead to biased estimates of price elasticities.

We use Australian household level panel data collected by the marketing research firm ACNielsen for SSB purchases over one year. The panel contains rich information on prices paid, quantities purchased, and household characteristics including income. We link this information with pre-existing data on caloric content of SSBs and body weight. The analysis proceeds in several stages. First, we derive price elasticities and cross-price elasticities for ten categories of non-alcoholic beverages with an Almost Ideal Demand System (AIDS). We use these elasticities to simulate the impact on consumption of all beverages that arise following the introduction of a $20 \%$ valoric tax, and a 20 cents/litre volumetric tax on SSBs. These estimates are then transformed in kilojoules and translated into reductions in individuals' weight. We then exploit the transaction level information for each product and compute the yearly financial burden due to the two different types of taxes at a household level. 
We find that a $20 \%$ valoric tax and a 20 cents/litre volumetric tax both lead to reductions in bodyweight - of around $0.5 \mathrm{~kg}$, and $0.9 \mathrm{~kg}$ per capita per year for an average consumer of SSBs, respectively. The tax burden under a $20 \%$ valoric tax and a 20 cents/litre volumetric tax is around $\$ 17$ and $\$ 11$ per capita per year, respectively. This means that despite the lower tax burden, the reduction in consumption and body weight is higher under a volumetric tax. This is an interesting result, even more interesting for high level consumers who lose even more weight for small marginal absolute dollar outlays, meaning interventions are very costeffective as we discuss in more detail in due course.

Our findings have important implications for policy makers who wish to maximise the positive health gains of such a tax while minimizing the adverse impacts on the welfare of their electorate.

\section{Background}

Taxes on unhealthy foods seem an attractive policy intervention as they not only promise positive health benefits, but also generate tax revenues for the government which can be invested in public health care. However, the positive health impacts and the financial burden of these taxes potentially vary by socio economic group. Thus it is imperative to analyse the distributional effects of food taxes to inform policymakers on the viability of these taxes and their distributional consequences.

Initial research, by Leicester and Windmeijer (2004), investigated the impact of a tax on consumption of saturated and unsaturated fat, sodium and cholesterol, foods that contain these, and the welfare impact on households by comparing pre- and post-tax expenditures on food. They find that a tax would be somewhat regressive; the very poorest $2 \%$ would see about $0.7 \%$ of their total income spent on the tax, whereas the very richest would pay less than $0.1 \%$ of their income. However, Leicester and Windmeijer's analysis does not estimate price elasticities, which means that they cannot take into account any behavioural responses to prices changes that are likely to affect consumption and welfare impacts.

Smed at al. (2007) compare the impact of different taxation schemes for the consumption of saturated fat, fibre and sugar on households in different age groups and social classes. They find the greatest improvement in diet composition for households of lower socioeconomic status and younger age. Results vary quite markedly by taxation scheme. Low social classes exhibit largest decreases in the demand for saturated fat in all schemes, but results are 
inconclusive with respect to demand for fibre and sugar. The study finds that the tax is progressive; this result is driven by the strong reduction in demand in younger households.

Nnoaham et al. (2009) examine the impact of four food taxation-subsidy regimes, by income group, on nutrition, health and expenditure in the UK. They find that a targeted food tax combined with an appropriate subsidy on fruit and vegetables could reduce deaths from cardiovascular diseases and cancer. However, all four regimens would be economically regressive and positive health effects will not necessarily be greater in lower-income groups where the need for dietary improvement is higher. The study has several imitations, importantly, it relies on secondary data sources for the estimates of elasticity that relate to a different observation period, and elasticities, consumption and expenditure data do not vary by income group.

Allais et al. (2010) estimate the impact of a fat tax on household purchases across a range of 22 food categories high in fat, and the resulting changes in consumption of nutrients and calories, and body weight. In addition, they estimate tax burdens. They find that demand is quite inelastic, although taxing cheese, butter and cream has a comparably large impact on calories purchased for well-off households, while for modest income households, taxing products that are high in both fat and sugar has a larger impact. Allais et al. further find that, although the tax would generate large revenues, it is regressive.

Nordström and Thunström (2011) model the impact of four hypothetical revenue-neutral tax reforms comprising of taxes on sugar and fat and a subsidy on grain. They find that the impact on dietary quality is difficult to evaluate and varies by income groups. The reforms would have positive health impacts, mainly due to increased fibre intake, but also unwarranted increase in the intake of sugar, salt and fat. For the lowest income group, the unwarranted health effects would over-compensate the positive ones. The authors find that all four reform scenarios would be progressive.

Zhen et al. (2011) extend the AIDS model to incorporate habit formation to assess the potential long-run impacts of a SSB tax on household beverage demand, expenditures and national tax revenue. They do not analyse regressivity of the tax, but they find that lowincome households are less elastic to price changes than those with a high-income.

Lin et al. (2011) examine the potential effects of a $20 \%$ valoric tax and the resultant taxinduced energy reductions and body weight with a dynamic demand model. They show that 
static models may overestimate the reduction in body weight by the tenth year after introduction of a tax on the order of 7.6 times over that of the dynamic model. According to this study the tax generates $\$ 5.8$ billion a year in revenue and is regressive, although in effect it represents only about $1 \%$ of household food and beverage spending.

A number of studies do not directly analyse the impact of taxes, but compare price sensitivity across income groups. Some find that cost constraints are a barrier to healthy eating among disadvantaged groups (Adelaja, Nayga et al. 1997, Darmon, Ferguson et al. 2002, Yen, Lin et al. 2004), while others find no significant differences in own-price elasticities across income groups (Park, Holcomb et al. 1996, Raper, Wanzala et al. 2002).

In summary, evidence on the welfare implications of taxes on unhealthy products is inconclusive, most likely due to data issues and methodological differences across studies. One possible source of differences that, surprisingly, is rarely mentioned is that the type of taxes under investigation varies across studies, with some analysing the impact of a volumetric tax (Leicester and Windmeijer 2004, Lin, Smith et al. 2011, Zhen, Wohlgenant et al. 2011), others a valoric tax (Nnoaham, Sacks et al. 2009, Allais, Bertail et al. 2010, Nordström and Thunström 2011), with one study considering both (Smed, Jensen et al. 2007). A second potential source of difference is that studies address very differently one of the most salient problems of demand system estimation: censored demand. Some households do not, or only infrequently, consume SSBs and thus their demand is censored at zero. None of the above studies have explicitly controlled for censored demand at household level. They circumvent the issue of censored demand by aggregating data in three main ways. Some studies aggregate purchase quantities and expenditures of all households over time, for example at a monthly level (Lin, Smith et al. 2011, Zhen, Wohlgenant et al. 2011). Some aggregate households into distinct categories based on one or usually several criteria such as age (Smed, Jensen et al. 2007, Lin, Smith et al. 2011), income (Leicester and Windmeijer 2004, Allais, Bertail et al. 2010, Lin, Smith et al. 2011, Nordström and Thunström 2011), region (Allais, Bertail et al. 2010) or social class (Smed, Jensen et al. 2007, Zhen, Wohlgenant et al. 2011). Nearly all studies aggregate food products into distinct categories. There is only one study, by Finkelstein et al. (2012), that allows explicitly for censored demand. However, this study uses a two-part model rather than a comprehensive demand system. Useful information on household purchasing behaviour is lost due to household aggregation, especially when censoring is the result of household economic decisions (Smed, Jensen et al. 2007, Zhen, Wohlgenant et al. 2011). Any simulation from such studies on 
household variables, and tax burden in particular (which depends on individual household purchasing behaviour), might perhaps be improved upon using disaggregated data.

Our study uses a household level censored demand model, controlling for a rich set of covariates and household characteristics, to estimate the impact of a $20 \%$ valoric tax, and a 20 cents per litre volumetric tax on consumption of ten categories of non-alcoholic beverages, and on body weight. This will shed light on two unresolved issues: whether estimates of the welfare implication varies by type of tax, and how results vary if censored demand is addressed with appropriate econometric methods. A further contribution is that we calculate the tax burden per capita attributed to the SSB tax not only for three categories of households (low income, middle income and high income) but also by beverage type.

\section{Data}

The analysis is undertaken using ACNielsen Homescan Panel Data collected from the state of Victoria, the second most populous in Australia. The data are collected from demographically representative households over a period of one year (between January 2010 and January 2011). ACNielsen conducts the Homescan survey in many countries (ACNielsen 2013). Homescan data is increasingly used for research into consumer behaviour in relation to food and nutrition for example to analyse the impact of taxes/subsidies on junk food and soft drink consumption (Dharmasena and Capps JR 2012, Finkelstein, Zhen et al. 2012), grain consumption (Nordström and Thunström 2009) and nutritional status (Smed, Jensen et al. 2007). The design of the Homescan survey is similar across countries: Household panel members are provided with a scanning device and are required to scan and record each item purchased at different retail locations (supermarkets, grocery stores, local shops etc.) over the specified time period. The Homescan dataset includes a unique level of detail on individual household purchases that is not provided in other publicly available population survey datasets, such as type, brand, flavour, size (millilitres), quantity, packaging (e.g. multi-pack), price paid per item (AUD\$), total spend per shopping trip, and the date and location (i.e. store name) of the shopping trip, along with social, demographic, economic and attitudinal information about the individual household and the shopper.

We use information on purchases of 10 types of beverages, including coffee and tea, but excluding alcoholic drinks. The information for each beverage includes its quantity, the price 
per unit, the store where it was purchased, the brand and up to six product characteristics (viz. diet drink, flavoured drink, sugar free etc.). In addition we have data on total expenditure on groceries and total expenditure on beverages for each shopping trip. The data also reports information on the social and demographic profile of the shopper and household head (age, gender, occupation, employment status), household income, presence of persons by age group in the household and a range of attitudinal information (exercise habits, nutritional and cooking attitudes). Data on household characteristics are collected annually.

Generally, researchers and policy makers make use of data from periodic population surveys that rely on self-reported household expenditure by food and/or beverage category to monitor and analyse beverage consumption. The limitations of such surveys are well documented and include several forms of bias, namely problems surrounding sampling, response, measurement, and recall, as well as issues with under-reporting of consumption by heavy drinkers (WHO 2000). Annual estimates of national per capita consumption of beverages provide a more reliable indicator of total consumption, but in many jurisdictions these are reported at a national population level only, thus constraining their usefulness for studying consumer behaviour in detail. The appeal of Homescan panel data, therefore, is that it overcomes some of the limits of existing surveys by collecting information on households' beverages purchased regularly over 52 weeks, and includes disaggregated detail about daily shopping trips and individual products purchased by each household. A validation study of Homescan data in the US found that households reported single purchases $99 \%$ accurately and multiple purchases $86 \%$ accurately (when checked against stores' sales records) (Einav, Leibtag et al. 2008). The small level of recording errors is similar to other research datasets for which cross-validation studies have been undertaken (Einav, Leibtag et al. 2008).

Our estimation sample consists of 1,390 households surveyed over a 52-week period. Following previous studies using Homescan data (Allais, Bertail et al. 2010) we aggregate purchases for each of the ten beverage categories at quarterly level. This gives four observations for each beverage category and household taking the total sample size to 5,560 observations. The quarterly expenditure and quantity consumed for each household are split by categories of non-alcoholic beverages. We consider ten categories of non-alcoholic beverages: i) regular soft drinks (non-diet soft drinks) which include standard soft drinks, mixers, sports drinks, energy drinks, still drinks and flavoured bottled water; ii) diet drinks which include diet/no-sugar/no-joule versions of regular soft drinks; iii) cordials which include mainstream, syrup, premium and powder sugar added cordials; iv) bottled water 
which includes plain unflavoured bottled water; v) fruit drinks; vi) fruit juices which include reconstituted, fresh and concentrated fruit juices; vii) high-fat milk which includes flavoured and plain types of full fat standard milk, soy milk and rice milk; viii) low-fat milk which includes reduced fat or no fat types of flavoured, plain, rice and soy milk; ix) tea which includes tea bags, instant and leaf organic and inorganic tea; and x) coffee which includes both reduced caffeine and caffeinated roast/ground and soluble coffee. We consider regular (non-diet) soft-drinks, cordial and fruit drink as SSBs in our study and assume that a policy of a SSB tax will affect prices of these three beverages only (although the tax may still affect consumption of the others).

Quantities for all non-alcoholic beverages are standardised in litres. ${ }^{2}$ Expenditure data are expressed in Australian dollars. ${ }^{3}$ Unit values (prices) are generated by taking the ratio between the expenditure for each non-alcoholic beverage and the quantity consumed. Prices are adjusted for inflation using the quarterly CPI deflator for food and non-alcoholic beverages. Budget shares are calculated as ratios of expenditure on a particular beverage to total expenditure on all ten non-alcoholic beverages. The sample is split into three subsamples based on household income quintiles. We define a household as "low-income" if their income falls in the bottom $20 \%$ (fifth quintile) of the household income distribution of the estimation sample, and as "high-income" if their income falls in the top $20 \%$. The rest of the households are considered to be middle-income households.

Table 1 provides descriptive statistics for quantity (litre per capita and per quarter), real unit values (\$/litre) and budget shares for each of the non-alcoholic beverage groups, by income group. Tea, coffee and milk were the most consumed non-alcoholic beverages at home followed by regular soft drinks. Total consumption of SSBs per household (adding up regular soft drink, cordial and fruit drink) at home is around 9.7 litres per quarter. Poorer households generally consume more. SSB consumption is 10.2 litres for low-income households and 7.95 litres for high-income households.

Fruit drinks and fruit juices are the most expensive non-alcoholic beverages whereas the cheapest are tea and cordials. Average unit prices paid by low-income households are generally lower than those paid by high-income households, though in some cases they are comparable (for example for diet soft drinks, cordial and fruit drink). This suggests that low-

\footnotetext{
${ }^{2}$ Consumption of tea and coffee is reported in tea cups and we assume that one tea cup is equivalent to $250 \mathrm{ml}$.

${ }^{3} 1$ Australian dollars is equivalent to around US\$ 1.00 USD and UK£0.65 in May 2013.
} 
income households buy cheaper products, or alternatively, prices for the same product may vary across retail outlets located in areas with differing socioeconomic profiles.

The budget share for SSBs (adding up regular soft drink, cordial and fruit drink) as a share of all beverages purchased is on average $18.7 \%$ for all households, slightly lower for lowincome and higher for middle-income households. Budget shares reflect the combined effect of variations in total consumption and unit prices paid across income groups. Table 2 reports mean household characteristics by income groups. In summary, these show that the average age of the shopper in low-income households is higher than the shopper in high-income households, that the main shopper in low income households is much less likely to have a full-time job, and that low income households spend most on non-alcoholic beverages consumed at home.

\section{Empirical Framework}

It is assumed that any change in body weight will result from a change in consumption of SSBs. Therefore as a first step we estimate the effect of a SSB tax on SSB consumption. This is done by estimating a demand system for quarterly household consumption of ten nonalcoholic beverages.

It should be noted that not all households consume all categories of beverages. The proportions of households not purchasing a SSB at least once over the year of observation is $8 \%$ for regular soft drinks, $11 \%$ for fruit drinks, and $43 \%$ for cordials. This means that for a small proportion of households in the cases of soft and fruit drinks, and nearly half for cordials, consumption and expenditure for that beverage is censored at zero.

Observed non-consumption might result from either infrequency of purchase by households (beverage not purchased during the survey period and consumed from stocks) or "genuine" non-consumption. The genuine non-consumption of a beverage might be attributed to noneconomic reasons such as taste and preferences, health considerations, (which remain unchanged post implementation of SSB tax) or to a corner solution where consumers in a household cannot afford a beverage at current income and prices. The dataset we use in this study provides information on household characteristics that include lifestyle variables such as cooking attitudes and exercise habits and purchasing pattern (whether a beverage was 
purchased as a multipack). This information can help identify the possible reasons leading to zero purchases in our sample period. The data for all non-alcoholic beverages shows that around $19 \%$ of total transactions were for multipacks. However cordials were purchased in a pack of 5, 10 or 15 in almost $98 \%$ of transactions indicating that households are more likely to stock up on cordials. Similarly, fruit drinks were purchased as multipacks (in a pack of 6,8 or 24) in $35 \%$ of transactions. Thus SSBs are more likely to be purchased as multipacks. We also look at the health conditions of households which might lead to non-consumption of SSBs. Around 12\% households report at least one member having diabetes, $6 \%$ report lactose intolerance, $23 \%$ having blood pressure issues and $28 \%$ having weight control issues. Moreover $30 \%$ of households not purchasing any SSBs report exercising to stay healthy whereas corresponding figure for purchasers of SSBs is $25 \%$. Thus households not consuming SSBs are more likely to be health conscious. Thus we assume that most of the zeroes for SSB purchase could be attributed to either purchasing patterns (household buying multipacks and stocking up), health conditions or health attitudes that are unlikely to change post SSB tax. On the other hand unaffordability of SSBs (leading to corner solutions) is unlikely in our case where prices of these beverages are very low with cordial costing just 50 cents per litre on an average.

Ignoring censoring and dropping observations with zero purchases could lead to a nonrandom sample and selection bias. We incorporate the censoring issue in demand estimation using a Heckman-type two-step method where in the first stage we model the binary decision to purchase a particular beverage as a function of detailed household characteristics with a probit model. Inverse Mills ratios (IMR) are derived from these models and are subsequently used as an additional regressor in the second-stage simultaneous equation demand system. One requirement of estimation of a complete demand system is the availability of prices for all beverages. However in the presence of censoring the prices/unit values (ratio of expenditure to quantity consumed) are missing as these cannot be calculated where consumption and expenditure are zero. We impute these prices using regression methods explained later in the paper. This censored demand approach is estimated using the functional form of The Almost Ideal Demand System (AIDS).

The own-price and cross-price elasticities from the censored demand system are then used to derive the impact of a $20 \%$ valoric tax and a 20 cents per litre volumetric tax (assumed to be imposed on regular soft-drinks, cordial and fruit drinks). This change in consumption is converted into quantity for each of the ten beverages. These quantities of beverages are then 
converted into the kilo Joule $(\mathrm{kJ})$ equivalents using calorie levels for $8 \mathrm{oz}$. of each nonalcoholic beverage as reported in Nutrition Tables of Australia (NUTTAB 2010), see Table A.1. The change in $\mathrm{kJ}$ for each beverage is summed to get the total net change in $\mathrm{kJ}$ for a person. Using the conversion ratio of $36,500 \mathrm{~kJ}$ per $\mathrm{kg}$ of body weight, the induced change in $\mathrm{kJ}$ per capita is converted into weight (in kgs). The tax burden arising from the SSB tax is derived using the transaction level information available for each beverage. Let us assume that the quantity purchased is adjusted from an initial level $q^{P}$ to a new level $q^{T}$ as a result of the SSB tax. We define tax burden as the difference between expenditure on purchasing amount $q^{T}$ post SSB tax and expenditure of purchasing $q^{P}$ pre SSB Tax.

The impact of SSB tax on body weight and tax burden for different income groups is calculated by repeating the above analysis on three sub-samples of the data (low income, middle income and high income).

\section{Demand System Model}

We first describe the standard AIDS model and then the modifications required to control for censored observations. The AIDS model in budget-share $w_{i h t}$ form, for beverage group $i$ consumed by household $h$ at time $t$, is given by:

$$
w_{i h t}=\mu_{i h}+\sum_{j=1}^{N} \gamma_{i j} \ln v_{j h t}+\beta_{i}\left[\ln x_{h t}-\ln a\left(v_{h t}\right)\right]+u_{i h t}
$$

With $i=1 \ldots . N$ beverages, $h=1 \ldots . H$ households and $t=1 \ldots 4$ quarters, and where:

- $\quad v_{i h t}$ is the unit value of a category of beverage-group $i$ for household $h$;

- $\ln \mathrm{a}\left(v_{h t}\right)$ is the Stone's (geometric price index) given by $\sum_{i=1}^{N} w_{i h t} \ln v_{i h t}$ (Deaton and Muellbauer 1980);

- $x_{h t}$ is total expenditure on non-alcoholic beverages of household $h$ in period $t$;

- $\quad \beta_{i}$ and $\gamma_{i}$ are the parameters to be estimated.

\section{Incorporating Demand Shifters}

The heterogeneity of household behaviour is taken into account by modelling parameter $\mu_{i h}$ as a linear form:

$$
\mu_{i h}=\alpha_{i 0}+Z_{h} \alpha_{i}
$$


where $\boldsymbol{Z}_{\boldsymbol{h}}=\left(Z_{k h}, k=1 \ldots . K\right)$ is a vector of household characteristics and seasonal dummies. This demand system is derived on the basis of cost minimization subject to the following restrictions on the functional form:

Homogenous of degree zero: $\sum_{j=1}^{N} \gamma_{i j}=0$

Additivity: $\quad \sum_{i=1}^{N} \alpha_{i 0}=1, \sum_{i=1}^{N} \alpha_{i}=0, \sum_{i=1}^{N} \gamma_{i j}=0$ for all $j$ and $\sum_{i=1}^{N} \beta_{i}=0$

Symmetry of Slustky's Matrix: $\gamma_{i j}=\gamma_{j i}$

Given these restrictions, in particular the additivity constraint, a complete demand system will have a singular variance-covariance matrix. Thus a demand system is estimated for $N-1$ beverage groups and parameters for the $N^{\text {th }}$ beverage-group are computed residually using an adding up restriction. The error term $u_{i h t}$ (conditional on household characteristics, prices and expenditure) is assumed to be i.i.d.

The effect of a SSB tax is derived from an uncompensated price elasticity matrix following the approach of (Banks, Blundell et al. 1997). The price elasticity of demand for beverage $i$ with respect to price $j$ is

$$
e_{i j, h, t}=-I_{i j}+\frac{1}{w_{i h}}\left[\gamma_{i j}-\beta_{i}\left(\mu_{i h}+\sum_{j=1}^{N} \gamma_{i j} \ln v_{j h t}\right)\right]
$$

where $I_{i j}$ equals 1 when $i=j$ and zero otherwise for all $i, j=1 \ldots . N ; \mu_{i h}=\alpha_{0}+\overline{Z_{h}} \alpha_{i}$. The elasticities are calculated at the sample mean of the estimated budget shares and household characteristics.

\section{Demand Estimation as a Censored Model}

\section{First Stage}

The decision to purchase beverage $i$ by household $h$ in quarter $t\left(\mu_{i h}\right)$ is modelled as:

$$
Y_{i h t}=f\left(\boldsymbol{Z}_{\boldsymbol{h}}, m_{h}\right)+u_{i h t}^{1}
$$


where $\boldsymbol{Z}_{\boldsymbol{h}}$ is a vector of socio-economic household characteristics which includes: shopper's age, if the shopper is female, if family type older single or couples, if young family, if the household resides in a regional area, if the shopper has a professional occupation, and household size. It also includes seasonal dummies (three for four quarters) and household income $m_{h}$.

The above equation is estimated as a probit model. The cumulative and probability density functions are used to derive the Inverse Mill's Ratio that takes value:

$$
I M R_{\text {iht }}=\frac{\varphi\left(\boldsymbol{Z}_{\boldsymbol{h}}, m_{h}\right)}{\Phi\left(\boldsymbol{Z}_{\boldsymbol{h}}, m_{h}\right)}
$$

if household h consumes beverage $i$ and value:

$$
I M R_{\text {iht }}=\frac{\varphi\left(\boldsymbol{Z}_{\boldsymbol{h}}, m_{h}\right)}{1-\Phi\left(\boldsymbol{Z}_{\boldsymbol{h}}, m_{h}\right)}
$$

if household h does not consume beverage $i$.

\section{$\underline{\text { Second Stage }}$}

The full specification of the censored model is:

$$
w_{i h t}=\alpha_{i 0}+Z_{\boldsymbol{h}} \boldsymbol{\alpha}_{\boldsymbol{i}}+\sum_{j=1}^{N} \gamma_{i j} \ln v_{j h t}+\beta_{i}\left[\ln x_{h t}-\ln a\left(v_{h t}\right)\right]+\delta_{i} I M R_{i h t}+u_{i h t}
$$

where IMR is included as an additional regressor in Eq. (1) and the value of $\mu_{i h}$ is substituted from Eq. (2). It should be noted that though Eq. (3) satisfies the homogeneity and symmetry conditions of the AIDS model (as discussed earlier) it does not satisfy the additivity condition. If all the $N$ equations in the demand system are specified using Eq. (3), the additivity condition will hold only if $\sum_{i=1}^{N} \delta_{i} I M R_{\text {iht }}=0$ which is not possible as $I M R_{\text {iht }}$ can take any value. Heien and Wessells (1990) suggest that this demand system should be also estimated for $N-1$ equations, however the specification for the $N^{t h}$ (deleted) equation should be modified as follows to preserve the additivity condition:

$w_{i h t}=\alpha_{i 0}+\boldsymbol{Z}_{\boldsymbol{h}} \boldsymbol{\alpha}_{\boldsymbol{i}}+\sum_{j=1}^{N} \gamma_{i j} \ln v_{j h t}+\beta_{i}\left[\ln x_{h t}-\ln a\left(v_{h t}\right)\right]-\sum_{j=1}^{N-1} \delta_{j} I M R_{j h t}+u_{i h t}$ 


\section{$\underline{\text { Imputation of missing prices }}$}

The missing prices are imputed by the procedure suggested by (Alviola, Oral et al. 2009): First, for households who purchased a particular beverage in a quarter, the price of that beverage is regressed on a set of household characteristics including shopper's age and gender, two dummy variables for household composition (if the household is a young family and if the household has older singles or couples only), one dummy variable which takes the value one if the household resides in a regional area, shopper's occupation, household size, seasonal dummies and household income. The coefficients from this regression capture the statistical association between household characteristics and the price of each beverage. Second, we use household characteristics of those households who did not consume the beverages to impute the missing prices for these households.

\section{Endogeneity of Expenditure}

The censored demand system is estimated in a simultaneous equation framework that assumes prices to be exogenous and quantity and expenditure to be endogenous for each beverage. Since total expenditure $\left(x_{t}\right)$ on beverages is the sum of expenditures on individual beverages it might be endogenous (Blundell and Robin 1999). We follow the standard procedure in the literature (Allais, Bertail et al. 2010, Dharmasena and Capps JR 2012) and remove possible endogeneity of total expenditure by predicting total expenditure through a regression wherein the natural $\log$ of per capita real total expenditure $\left(\ln x_{h t}\right)$ is regressed on the natural $\log$ of the real price of all non-alcoholic beverages $\left(v_{i n t}\right)$, and the natural $\log$ of real per capita income, $\ln m_{h t}$, and household characteristics. The quarterly prices and expenditure are converted into real terms by using quarterly CPI deflator for food and nonalcoholic beverages for the appropriate geographic region (Melbourne) (ABS 2013).

\section{Valoric and volumetric tax comparison}

We estimate the above model for the impact of a $20 \%$ valoric (sometimes referred to as 'value added', or a 'flat rate') tax, and a 20 cents/litre volumetric tax for the whole sample, assuming that elasticities are the same across the sample. Our primary analysis to examine the change in consumption, body weight and tax burden is undertaken assuming a $20 \%$ valoric tax, based on the National Preventive Health Strategy (National Preventative Task Force) in Australia and others recommending a 20\% valoric tax. Thus our estimates simulate this policy scenario to inform policy makers and to enable comparison with findings in the literature as the majority of previous studies have used a $20 \%$ valoric tax. We subsequently 
present results for a 20 cents/litre volumetric tax. A recent report prepared by 61 organisations in the UK has recommended an excise duty based on volume (volumetric tax) as opposed to a sales tax (20\% valoric tax).

Sustain (Sustain 2013) put forward the following argument in favour of a volumetric tax: "Although the effect of a $20 \%$ sales tax is greater than the excise duty in making smaller volumes (single cans) of sugary drinks more expensive, the excise duty results in much larger increases in price for larger volumes purchased, even where special offers apply". We use this to illustrate that a similar sounding amount of tax ( $20 \%$ or 20 cents per litre) can have very different real world effects depending on the type of tax (valoric or volume) introduced. This is illustrated in our Results section below. Further, we estimate results separately for three income groups (low, middle and high), assuming different elasticities for the groups.

\section{Results}

\section{Price Elasticities}

Table 3 reports uncompensated own-price and cross-price elasticities for ten non-alcoholic beverages when the whole sample is used. Own-price elasticities are reported in the diagonal and indicate the percentage change in quantity consumed as a result of a 1 per cent change in price of the corresponding beverage. Cross-price elasticities are reported off the diagonal and indicate the percentage change in quantity consumed of the beverage listed in the first column as a 1 per cent change in price of the beverage listed in the first row. Our results show that own-price elasticities indicate elastic demand (elasticities in absolute values bigger than 1) for all beverages except for regular soft-drink. They range from -0.88 for regular soft-drink to -2.23 for cordial. ${ }^{4}$ All own-price elasticities are significantly different from zero. Out of 90 cross-price elasticities 69 are significantly different from zero. Cross-price elasticities for the following pairs of beverages are positive making them substitutes in consumption: low-fat milk and high-fat milk; tea and coffee; fruit drink and fruit juice. Interestingly, bottled water is a substitute in consumption to regular soft-drinks, cordial, fruit drink and fruit juice suggesting that consumption of bottled water will increase in response to an increase in price of regular soft-drinks, cordial, fruit drink and fruit juice. The cross-price elasticity between

\footnotetext{
${ }^{4}$ It should be noted that both high-fat and low-fat milk include flavoured milk, Soy milk and Rice milk which might make their demand elastic.
} 
regular soft drinks and diet soft drinks is negative (making them complements) though the elasticity is small and not statistically significant. This negative sign is consistent with past studies (Dharmasena and Capps JR 2012). Similarly, fruit drinks and regular soft drinks are also complements (the elasticity is very small in absolute terms but statistically significant) whereas fruit drinks and diet soft drinks are substitutes.

\section{Impact of household characteristics and purchasing patterns on budget share}

Table 4 reports the impact of household characteristics on budget shares for each beverage. Households where the main shopper is female, above 40 years of age or not in full employment are likely to have lower budget shares for soft drinks and fruit drinks. Soft drinks have higher budget shares in the fourth quarter. The gender of a shopper has a significant effect on budget shares of almost all beverages. Ceteris paribus a household with a female shopper will have a higher budget share for diet drinks, cordial, bottled water, fruit drinks and coffee, and a lower budget share for regular soft drinks, fruit juice and high-fat milk. Household with young shoppers (aged less than 40 years) are likely to have higher budget shares for regular soft drinks, cordial, bottled water and fruit drinks, and a lower budget share for (at-home purchase of) tea and coffee. Young families, relative to other households, have a higher budget share of cordial, fruit drinks, high-fat milk and a lower budget share of diet soft drinks, low fat milk, tea and coffee. Households with a shopper in a full time occupation will have a higher budget share of regular and diet soft drinks, fruit juice and a lower budget share for (at-home purchase of) tea and coffee. Regular and diet soft drinks, cordial and bottled water have higher budget shares in the fourth quarter (October to December- Spring/Summer) compared to previous three quarters. IMR has a significant effect on all beverages and has an expected positive sign indicating that propensity to purchase a certain beverage by a household is likely to increase the budget share of that beverage.

\section{Impact of a $20 \%$ valoric tax on SSBs on consumption of beverages}

We now use the elasticity estimates to examine whether a proposed $20 \%$ valoric tax on SSBs will alter household consumption of SSBs and, if it does, what will be the consequences of such a policy for other non-SSBs such as bottled water, milk, tea and coffee. We consider regular soft-drinks, cordial and fruit drinks as SSBs, and assume that as a result of the $20 \%$ tax, prices of these three beverages will rise by $20 \%$, i.e. we assume that taxes are fully 
passed on by the beverage industry and retailers and that they do not absorb the taxes. ${ }^{5}$ Table 5 reports (i) the direct effects, i.e. the effect of the SSB tax on SSB consumption, (ii) the indirect effect, i.e. the substitution effect which arises from substituting consumption to nonSSB beverages or substituting consumption to other SSB beverages, and (iii) the total effect, which is the sum of the above. These effects are expressed in percentage changes in quantities of all ten non-alcoholic beverages once the $20 \%$ tax is applied on regular soft drinks, cordial and fruit drinks. Negative (positive) values indicate a reduction (increase) in beverage consumption. The direct effects (column 2, table 5) for the three taxed beverages show that a $20 \%$ increase in price will lead to reductions in consumption of $17.67 \%, 46.5 \%$ and $20.03 \%$ of regular soft drinks, cordial and fruit juice respectively.

The consumption of the taxed SSBs is also affected indirectly through cross-price elasticities. For example a $20 \%$ increase in the price of cordial will reduce consumption of fruit drink by a further $3.33 \%$ since cordial and fruit drinks are complements (using the estimate of crossprice elasticity of -0.167 from Table 3 ) generating a total reduction in consumption of fruit drinks by $23.36 \%$. Similarly, a $20 \%$ increase in fruit drinks will reduce consumption of cordial by a further $4.83 \%$ generating a total reduction in consumption of cordial by $51.4 \%$.

The consumption of beverages which are not subject to the SSB tax will also change, but only indirectly through cross-price elasticities. These indirect effects are reported in the third column of Table 5 for each beverage. Since most beverages are substitutes, the consumption of most non-taxed beverages increases as a result of the tax. The magnitudes of the effects are generally small except for bottled water for which consumption increases by $23 \%$. This suggests that households will switch to a no-joule healthier beverage as a result of SSB tax which is a positive outcome from the perspective of obesity reduction strategy.

\section{Impact of a $20 \%$ valoric tax on SSBs on kilo joule consumption and body weight}

We use the total effect on consumption of non-alcoholic beverages to calculate the corresponding reduction in kilo joules per capita per quarter as a result of the valoric tax. The change in net kilo joules is then translated into change in body weight (per capita and per year). The weight change is calculated at two levels of consumption: mean consumption

\footnotetext{
${ }^{5}$ The recent literature on incidence of commodity taxation has found pass-through rates close to 1, Harding, M., E. Leibtag and M. F. Lovenheim (2012). "The heterogeneous geographic and socioeconomic incidence of cigarette taxes: Evidence from Nielsen Homescan data." American Economic Journal: Economic Policy 4(4): 169-198.
} 
(reflecting consumption by an average person) and consumption level at 95th percentile (reflecting consumption by heavy drinkers of non-alcoholic beverages).

For an average consumer of beverages, the tax will result in a reduction in consumption of regular soft drinks, cordial, fruit drink and coffee by 1.02 litres (lt), $1.66 \mathrm{lt}, 0.15 \mathrm{lt}$ and $0.80 \mathrm{lt}$ respectively, per person per quarter. Note that although the elasticity for regular soft drinks and fruit drinks is similar (and slightly higher for the latter) the average consumption of fruit drinks is much lower (0.65 litres versus 5.8 litres). This explains why fruit drink consumption reduces only by 0.15 lt. By contrast, coffee consumption is high and about 21.3 litres. Therefore, even a small elasticity implies a reduction of 0.8 litres.

These reductions in quantities are then converted to $\mathrm{kJ}$ equivalents using the conversion values reported in Nutritional Tables for Australia (NUTTAB 2010). ${ }^{6}$ The results are reported in Table 6. These correspond to a reduction of 1,626 kJ, 2,384 kJ, $264 \mathrm{~kJ}$ and $48 \mathrm{~kJ}$ for regular soft drinks, cordial, fruit drink and coffee respectively. This corresponds to a total reduction of 4,322 $\mathrm{kJ}$. Therefore, the largest reductions in $\mathrm{kJ}$ are driven by reductions in consumption in regular soft drinks and cordial and only to a minor extent by fruit drinks (due to low consumption) and coffee (due to low calorie content). The valoric tax also leads to small or moderate increases in consumption of diet drinks, bottled water, fruit juices, low-fat milk and tea by $0.04 \mathrm{lt}, 0.20 \mathrm{lt}, 0.01 \mathrm{lt}, 0.13 \mathrm{lt}$ and $0.07 \mathrm{lt}$ respectively which corresponds to an increase of $300 \mathrm{~kJ}$. The overall substitution effect to other beverages is therefore modest and thus the net $\mathrm{kJ}$ reduction arising from the SSB tax is $4,022 \mathrm{~kJ}$ per quarter $(4,322-300)$ or $16,087 \mathrm{~kJ}$ per year.

(Lin, Smith et al. 2011) suggest that a reduction of $36,500 \mathrm{~kJ}$ per year (100kJ/day) will lead to a reduction in body weight by $1 \mathrm{Kg}$. Using this conversion criteria a reduction of $16,087 \mathrm{~kJ}$ as a result of the SSB tax translates into a reduction in body weight of $0.44 \mathrm{Kg}$ $(16,087 / 36,500 \mathrm{Kj})$ per year at mean level of consumption.

Table 5 also provides the corresponding reduction in $\mathrm{kJ}$ and body weight at the 95th percentile of beverage consumption, to illustrate the effects on high level consumers. The per capita quarterly consumption of regular soft drinks, cordial and fruit drink at the $95^{\text {th }}$ percentile is $24.25 \mathrm{lt}, 17.5 \mathrm{lt}$ and $3.72 \mathrm{lt}$ respectively which reduces by $4.2 \mathrm{lt}, 8.14 \mathrm{lt}$ and 0.74

\footnotetext{
${ }^{6}$ The values are similar to those reported by Smith, T., B.-H. Lin and J.-Y. Lee (2010). "Taxing caloric sweetened beverages: Potential effects on beverage consumption, calorie intake, and obesity." USDA-ERS Economic Research Report(100).for the US data which are reported in the second column of Table A.1.
} 
lt respectively as a result of a $20 \%$ valoric tax. This translates into an overall yearly reduction in per capita consumption equivalent to $81,300 \mathrm{~kJ}$ and a reduction in body weight of $2.22 \mathrm{Kg}$. Thus the per capita, per year, weight loss as a result of the tax is almost six times greater for heavy drinkers relative to persons drinking at an average level. This is a significant positive effect, considering that heavy drinkers would be a major target group for any tax policy.

As an additional sensitivity analysis, we also investigate whether households with children respond differently to a SSB tax. We re-estimate the demand system for three different subgroups: i) Young family with at least one child aged less than or equal to 11 years; ii) Older family with all children older than 11 years and iii) households with no children. The total effects of a $20 \%$ valoric tax along with corresponding change in weight are reported in Table A.2. The results are similar across the three groups. The reduction in soft drinks, cordial and fruit drink are of similar magnitude and this also applies to the reduction in body weight which varies between 0.41 and $0.45 \mathrm{Kgs}^{7}$

\section{The impact of a $20 \%$ valoric tax on consumption and bodyweight by Income}

\section{Groups}

We split the sample into three groups (low, middle and high income households) based on household income and estimate a censored demand system separately for each sub-group. Subsequently, we calculate the impact of the SSB tax on consumption and body weight using the same methodology outlined above. Table 7 reports the effects of the $20 \%$ valoric tax on quantity of non-alcoholic beverages purchased, by income groups. The results reveal that the response to the tax varies by income group. The demand for regular soft drinks is slightly less responsive for low-income households: the reduction in consumption (as a result of 20\% valoric tax) is $16.68 \%$ for low-income households, $17.97 \%$ for middle-income households and $18.58 \%$ for high-income households. Differences are more pronounced for cordial and fruit drinks. Here, it is the high-income households who have the least elastic demand. The reduction in consumption for fruit drinks is $19.66 \%$ for high-income households, less than half of that for low-income households $(43.36 \%)$. Results for middle-income households (which account for the majority of the sample) are similar to high-income households. For

\footnotetext{
${ }^{7}$ We also re-estimate the demand system without using the Inverse Mills ratio to test the sensitivity of our estimates to any selection bias caused by censored data. The results show that although the total effect of a $20 \%$ SSB tax on cordials and bottled water is underestimated or lower once we ignore IMR, the overall effect on change in body weight is of the same magnitude (around $0.4 \mathrm{Kgs}$ ). These results are available from the corresponding author.
} 
cordial the reduction in consumption is $32.75 \%$ for low income households, which is lower than for high-income households $(53.37 \%)$. Middle-income households have the strongest response $(56.02 \%)$.

The overall corresponding reductions in body weight (presented in Table 8) are similar at sample means for low (around $0.43 \mathrm{~kg}$ ) and middle income households (around $0.5 \mathrm{~kg}$ ), but almost half (around $0.23 \mathrm{Kgs}$ ) for high income households. This can mainly be attributed to differences in quantities consumed by income groups: for example, while high-income households respond more to the tax in percentage points for cordial and fruit drinks, they consume less of those beverages overall (see Table 1). The reduction in weight for heavy drinkers of non-alcoholic beverages is $2.4 \mathrm{kgs}, 2.6 \mathrm{kgs}$ and $1.2 \mathrm{kgs}$ for low income, middle income and high income households respectively. Again, the comparably low reduction in bodyweight for high-income households is explained by lower levels of consumption. A notable result is that only middle income households (who account for $60 \%$ of the sample) increase consumption of bottled water as a result of the $20 \%$ valoric tax.

\section{The impact of a $20 \%$ SSB valoric tax on tax burden by income groups}

Table 9 reports the average tax burden by income group and beverage type (per capita and per year) ${ }^{8}$. Two values of the tax burden are reported: the mean value and the value at the 95th percentile of the tax burden distribution. The results show that the average tax burden in absolute terms is low. It is highest for low-income households both in magnitude and as a proportion of income. Low-income households pay $\$ 17.87$ per capita per year as SSB tax compared to $\$ 17.23$ and $\$ 15.17$ for middle and high income households. In terms of proportion of income this corresponds to $0.21 \%$ of the income for low-income households, $0.07 \%$ for middle-income households and $0.06 \%$ for high-income households. The difference between tax burdens across income groups further widens at the 95th percentile, making this tax regressive if evaluated as a proportion of income - however the absolute differences are negligible in dollar values over a year.

\footnotetext{
${ }^{8}$ We define tax burden as the additional cost of beverage attributed to SSB tax. For example if a beverage's price increases from $\$ 1$ to $\$ 1.20$ after a valoric tax, the tax burden on a $800 \mathrm{ml}$ beverage will be the difference between the cost of $800 \mathrm{ml}$ beverage after tax $(\$ 0.8 * 1.2=\$ 0.96)$ and the cost of $800 \mathrm{ml}$ beverage before tax $(\$ 0.8 * 1=\$ 0.80)$ which is $\$ 0.16$. The tax burden is aggregated over all transactions for each household and divided by household size to derive a per capita value of tax burden.
} 


\section{Comparison to a Volumetric Tax}

Using the methods described earlier we estimate the effect of a per litre volumetric tax of 20 cents on SSBs 9 . It is important to emphasise that whether the absolute value of the price increase is higher under a per litre volumetric tax of 20 cents or under a $20 \%$ price increase depends critically on whether the (average) price per litre is above or below one dollar. We can see from Table 1 that the average price per litre is above one dollar for soft drinks and fruit drinks but is below one for cordial. This implies that the price change will be higher for cordial under a 20 cents price increase and it will be higher for soft and fruit drinks under a $20 \%$ increase. In turn, given our elasticity estimates, it implies that the quantity reductions in beverage consumptions will be higher for soft and fruit drinks (lower for cordial) under a $20 \%$ price increase. In our case the average price of regular soft drinks increases by an average $19.66 \%$ under volumetric tax which is close to the price increase of $20 \%$ under a valoric tax. On the other hand, for cordials which are mostly purchased as multi packs by households in our sample, the average price is $\$ 0.50$ per litre which increases to $\$ 0.70$ per litre (an increase of 40\%) under volumetric tax. The average price of fruit drinks (which costs around $\$ 2$ ) increases by $12 \%$ under a volumetric tax.

Table 9 compares the changes in body weight that arise as a result of the two taxes. Since soft drinks and fruit drink consumption is lower under a volumetric tax but cordial consumption is higher, whether overall weight increases or decreases is in principle indeterminate. Table 10 shows that the higher consumption on cordial dominates and overall the change in weight is higher under a volumetric tax. This is due to the relatively high caloric content of cordial. More precisely, for low-income groups, the additional reduction in bodyweight brought about the volumetric tax is $87 \%$ above the reduction achieved with the sales tax, which in absolute terms is just under half a kg per year. For middle-income groups, the additional reduction achieved is higher, but for high-income groups lower.

Table 10 also presents the tax burden as a result of the volumetric tax for all households as well as three income groups. The corresponding changes under the $20 \%$ valoric tax are also

\footnotetext{
${ }^{9}$ As an example, the Sustain Sustain (2013). A Children's Future Fund: How food duties could provide the money to protect children's health and the world they grow up in.report compares the change in price of a four pack 2 litre Sainsbury cola (total amount 8 litres) under a valoric and volumetric tax. A valoric tax of $20 \%$ is $£ 0.40$ which increases the price from UK£1.99 to $£ 2.39$, a $2.5 \%$ increase in price/litre, whereas a volumetric tax of 20 p/litre on 8 litre of cola is $£ 1.60$ which increases the price of cola from $£ 1.99$ to $£ 3.59$, an increase of $10.1 \%$ in price per litre.
} 
reported for comparison. The estimates show that although both taxes are regressive in proportional terms, the tax burden is lower under a 20 cents/litre volumetric tax than a $20 \%$ sales tax. For low-, middle- and high-income households, the tax burden for soft drinks under the volumetric tax is $16 \%, 25 \%$ and $30 \%$ lower in comparison to the sales tax. While the differences in tax burden between the two taxes seem high in percentage changes, the difference in absolute (annual) monetary terms are inconsequential (at \$1.98, \$2.97 and \$2.79 per annum for low-, middle- and high-income groups, respectively).

\section{Conclusions}

This paper estimates the impact of two SSB taxes on consumption of 10 categories of nonalcoholic beverages as well as the effect of such tax on body weight for different income groups. The associated tax burden is also calculated as a proportion of income to determine the extent to which the taxes are regressive. One main contribution of the paper is to compare the impact of two types of taxes, a valoric (sales) tax on price and a volumetric tax on quantity, on consumption of beverages, kilojoule intake, bodyweight, and tax burden. A key methodological contribution of this paper is to control for censored demand (when households do not consume a particular beverage), which allows to use information on even those households in the analysis which consume less than 10 non-alcoholic beverages over the year. The estimates are generated using an Almost Ideal Demand System and a two-step approach where the first step models the probability of purchasing a particular beverage and quantifies the selection bias using IMR. The second stage subsequently uses this IMR in a censored demand system which generates own-price and cross-price elasticities.

The main finding of the study is that a $20 \%$ increase in price of SSBs via a valoric tax would result in a decrease of $16,087 \mathrm{~kJ}$ of energy intake at average levels of SSB consumption and $81,300 \mathrm{~kJ}$ decrease at the 95th percentile of consumption. This translates into a weight reduction of $0.44 \mathrm{~kg}$ for average SSB purchasers and $2.22 \mathrm{~kg}$ for heavy SSB purchasers of non-alcoholic beverages. There is significant substitution (a 23\% increase) towards bottled water as a result of the tax. Indirect substitutions to other high calorie beverages (viz. high fat milk and fruit juice) are small in magnitude.

The sub-group analysis reveals that low-income households have the least elastic demand for regular soft drinks. The reduction in weight by average purchasers of SSBs is around $0.5 \mathrm{kgs}$ 
per year for low and middle income groups and $0.23 \mathrm{kgs}$ for high income groups. For heavy purchasers of SSBs from low and middle income groups the weight reduction (around 2.4 $\mathrm{Kgs})$ is almost double that of heavy purchasers belonging to high income households (1.2 $\mathrm{Kgs})$. Average SSB tax burden for low income households is around \$18 per capita per year ( $0.21 \%$ of their household income), and $\$ 15.17$ for high income households $(0.025 \%$ of household income). While in absolute terms these differences in tax burden are negligible, the population wide per capita average yearly weight reduction of around $0.5 \mathrm{Kgs}$ is significant. In comparison, we find that a 20 cents/litre volumetric tax is associated with an even lower tax burden and a relatively higher reduction in body weight. Cost of implementation and administration could however be higher for a volumetric tax.

In summary, our findings show that taxing SSBs is a policy intervention that promises significant positive impacts on public health, with negligible negative impacts on household income and inequality in wealth. While the taxes are mildly regressive, i.e. burden lowincome households more in relative terms, the overall monetary amounts are negligible. We find clear evidence of positive behavioural responses by households to SSB taxes which leads to measurable reductions in consumption of SSBs and weight loss. Heavy purchasers of SSBs, in particular from low income groups, will experience even greater weight reductions. The tax revenues from SSB taxes can be used for the implementation of additional public health policies. We conclude that policy makers should consider SSB taxes as one of the effective policy interventions that help curb the rise in obesity rates, for the benefit of population health. 


\section{References}

ABS. (2013). "Consumer Price Index, Australia." Retrieved Feb 26 2013, from http://www.abs.gov.au/AUSSTATS/abs@.nsf/DetailsPage/6401.0Dec\%202012?OpenDocument.

ACNielsen. (2013). Retrieved 25 Feb 2013, from http://homescan.acnielsen.com.au/.

Adelaja, A. O., R. M. Nayga and T. C. Lauderbach (1997). "Income and Racial Differentials in Selected Nutrient Intakes." American Journal of Agricultural Economics 79(5): 1452-1460.

Allais, O., P. Bertail and V. Nichèle (2010). "The Effects of a Fat Tax on French Households' Purchases: A Nutritional Approach." American Journal of Agricultural Economics 92(1): 228-245.

Allison, D. B. and R. D. Mattes (2009). "Nutritively sweetened beverage consumption and obesity: The need for solid evidence on a fluid issue." JAMA 301(3): 318-320.

Alviola, P. A., C. Oral and X. Wu (2009). Micro-Demand Systems Analysis of Non-Alcoholic Beverages in the United States: An Application of Econometric Techniques Dealing With Censoring. Agricultural and Applied Economics Association 2010 Annual Meeting, July 25-27, 2010. Denver, Colorado, Agricultural and Applied Economics Association.

Americans Against Food Taxes. (2013). "Americans Agains Food Taxes Education." Retrieved 28/01/2013, from http://www.nofoodtaxes.com/facts/\#education.

Banks, J., R. Blundell and A. Lewbel (1997). "Quadratic Engel Curves and Consumer Demand." Review of Economics and Statistics 79(4): 527-539.

Blundell, R. and J. M. Robin (1999). "Estimation in large and disaggregated demand systems: an estimator for conditionally linear systems." Journal of Applied Econometrics 14(3): 209-232.

Bridging the Gap Program (2011). State Sales Tax on Regular, Sugar-Sweetened Soda (as of July 1 , 2011). U. o. I. a. Chicago.

British Heart Foundation (2012). Coronary Heart Disease Statistics 2012. Coronary Heart Disease Statistics B. H. Foundation.

Brownell, K. D. and T. R. Frieden (2009). "Ounces of Prevention - The Public Policy Case for Taxes on Sugared Beverages." New England Journal of Medicine 360(18): 1805-1808.

Brownell, K. D. and K. E. Warner (2009). "The Perils of Ignoring History: Big Tobacco Played Dirty and Millions Died. How Similar Is Big Food?" Milbank Quarterly 87(1): 259-294.

Center for Responsive Politics. (2013). "Lobbying - Industry: Food Processing and Sales." Influence \& Lobbying Retrieved 29/01/2013, from http://www.opensecrets.org/lobby/indusclient.php?id=A09\&year=2009.

Darmon, N., E. L. Ferguson and A. Briend (2002). "A Cost Constraint Alone Has Adverse Effects on Food Selection and Nutrient Density: An Analysis of Human Diets by Linear Programming." The Journal of Nutrition 132(12): 3764-3771.

Deaton, A. and J. Muellbauer (1980). "An almost ideal demand system." The American economic review 70(3): 312-326.

Dharmasena, S. and O. Capps JR (2012). "Intended and unintended consequences of a proposed national tax on sugar - sweetened beverages to combat the US obesity problem." Health Economics 21(6): 669-694.

Einav, L., E. Leibtag and A. Nevo (2008). On the accuracy of Nielsen Homescan data, USDA, Economic Research Service.

Finkelstein, E. A., C. Zhen, M. Bilger, J. Nonnemaker, A. M. Farooqui and J. E. Todd (2012). "Implications of a sugar-sweetened beverage (SSB) tax when substitutions to non-beverage items are considered." Journal of Health Economics.

Harding, M., E. Leibtag and M. F. Lovenheim (2012). "The heterogeneous geographic and socioeconomic incidence of cigarette taxes: Evidence from Nielsen Homescan data." American Economic Journal: Economic Policy 4(4): 169-198.

Heien, D. and C. R. Wessells (1990). "Demand Systems Estimation with Microdata: A Censored Regression Approach." Journal of Business \& Economic Statistics 8(3): 365-371. 
Khazan, O. (2012). What the world can learn from Denmark's failed fat tax. The Washington Post. Laurance, J. (2009). "Time for a fat tax?" The Lancet 373(9675): 1597.

Leicester, A. and F. Windmeijer (2004). The 'fat tax': economic incentives to reduce obesity. IFS Briefing Notes BN49. I. o. F. Studies. London, UK, Institute of Fiscal Studies.

Lin, B. H., T. A. Smith, J. Y. Lee and K. D. Hall (2011). "Measuring weight outcomes for obesity intervention strategies: the case of a sugar-sweetened beverage tax." Economics and human biology 9(4): 329-341.

Mytton, O. T., D. Clarke and M. Rayner (2012). "Taxing unhealthy food and drinks to improve health." $\underline{B M J} 344$.

National Preventative Task Force Australia: The Healtiest Country by 2020. A. G. D. o. H. a. Ageing. Canberra.

Nnoaham, K. E., G. Sacks, M. Rayner, O. Mytton and A. Gray (2009). "Modelling income group differences in the health and economic impacts of targeted food taxes and subsidies." International Journal of Epidemiology 38(5): 1324-1333.

Nordström, J. and L. Thunström (2009). "The impact of tax reforms designed to encourage healthier grain consumption." Journal of Health Economics 28(3): 622-634.

Nordström, J. and L. Thunström (2011). "Can targeted food taxes and subsidies improve the diet? Distributional effects among income groups." Food Policy 36(2): 259-271.

NUTTAB. (2010). Retrieved 15 December 2012, from http://www.foodstandards.gov.au/science/monitoringnutrients/nutrientables/nuttab/Pages/default .aspx.

Park, J. L., R. B. Holcomb, K. C. Raper and O. Capps (1996). "A Demand Systems Analysis of Food Commodities by U.S. Households Segmented by Income." American Journal of Agricultural Economics 78(2): 290-300.

Powell, L. M. and F. J. Chaloupka (2009). "Food Prices and Obesity: Evidence and Policy Implications for Taxes and Subsidies." Milbank Quarterly 87(1): 229-257.

Press Association (2011). UK could introduce 'fat tax', says David Cameron. The Guardian.

Raper, K. C., M. N. Wanzala and R. M. Nayga (2002). "Food expenditures and household demographic composition in the US: a demand systems approach." Applied Economics 34(8): 981992.

Sharma, L. L., S. P. Teret and K. D. Brownell (2010). "The Food Industry and Self-Regulation: Standards to Promote Success and to Avoid Public Health Failures." American Journal of Public Health 100(2): 240-246.

Smed, S., J. D. Jensen and S. Denver (2007). "Socio-economic characteristics and the effect of taxation as a health policy instrument." Food Policy 32(5-6): 624-639.

Smith, T., B.-H. Lin and J.-Y. Lee (2010). "Taxing caloric sweetened beverages: Potential effects on beverage consumption, calorie intake, and obesity." USDA-ERS Economic Research Report(100).

Sustain (2013). A Children's Future Fund: How food duties could provide the money to protect children's health and the world they grow up in.

Thow, A. M., P. Heywood, S. Leeder and L. Burns (2011). "The global context for public health nutrition taxation." Public Health Nutrition 14(01): 176-186.

United Nations (2011). Prevention and control of non-communicable diseases, United Nations.

Vartanian, L. R., M. B. Schwartz and K. D. Brownell (2007). "Effects of Soft Drink Consumption on Nutrition and Health: A Systematic Review and Meta-Analysis." American Journal of Public Health 97(4): 667-675.

WHO (2000). International Guide for Monitoring Alcohol and Related Harm. Geneva, World Health Organization.

Yen, S. T., B.-H. Lin, D. M. Smallwood and M. Andrews (2004). "Demand for nonalcoholic beverages: The case of low-income households." Agribusiness 20(3): 309-321.

Zhen, C., M. K. Wohlgenant, S. Karns and P. Kaufman (2011). "Habit Formation and Demand for Sugar-Sweetened Beverages." American Journal of Agricultural Economics 93(1): 175-193. 
